\title{
Waste Materials from Tetra Pak Packages as Reinforcement of Polymer Concrete
}

\author{
Miguel Martínez-López, ${ }^{1}$ Gonzalo Martínez-Barrera, ${ }^{2}$ Carlos Barrera-Díaz, ${ }^{3}$ \\ Fernando Ureña-Núñez, ${ }^{4}$ and Witold Brostow ${ }^{5}$ \\ ${ }^{1}$ Facultad de Química, Universidad Autónoma del Estado de México, Paseo Colón Esquina, Paseo Tollocan, S/N, \\ 50120 Toluca, MEX, Mexico \\ ${ }^{2}$ Laboratorio de Investigación y Desarrollo de Materiales Avanzados (LIDMA), Facultad de Química, \\ Universidad Autónoma del Estado de México, $\mathrm{km} 12$ de la Carretera, Toluca-Atlacomulco, 50200 San Cayetano, MEX, Mexico \\ ${ }^{3}$ Centro Conjunto de Investigación en Química Sustentable UAEM-UNAM, Universidad Autónoma del Estado de México, \\ Campus El Rosedal, Autopista Ixtlahuaca-Atlacomulco, km 14.5, 50200 Toluca, MEX, Mexico \\ ${ }^{4}$ Instituto Nacional de Investigaciones Nucleares, Carretera México-Toluca, S/N, 52750 La Marquesa Ocoyoacac, MEX, Mexico \\ ${ }^{5}$ Laboratory of Advanced Polymers \& Optimized Materials (LAPOM), Department of Materials Science and \\ Engineering and Center for Advanced Research and Technology (CART), University of North Texas, 1150 Union Circle No. \\ 305310, Denton, TX 76203-5017, USA
}

Correspondence should be addressed to Gonzalo Martínez-Barrera; gonzomartinez02@yahoo.com.mx

Received 5 May 2015; Revised 5 August 2015; Accepted 28 September 2015

Academic Editor: Cornelia Vasile

Copyright (C) 2015 Miguel Martínez-López et al. This is an open access article distributed under the Creative Commons Attribution License, which permits unrestricted use, distribution, and reproduction in any medium, provided the original work is properly cited.

Different concentrations (from 1 to $6 \mathrm{wt} \%)$ and sizes $(0.85,1.40$, and $2.36 \mathrm{~mm}$ ) of waste Tetra Pak particles replaced partially silica sand in polymer concrete. As is well known, Tetra Pak packages are made up of three raw materials: cellulose (75\%), low density polyethylene (20\%), and aluminum (5\%). The polymer concrete specimens were elaborated with unsaturated polyester resin $(20 \%)$ and silica sand (80\%) and irradiated by using gamma rays at 100 and $200 \mathrm{kGy}$. The obtained results have shown that compressive and flexural strength and modulus of elasticity decrease gradually, when either Tetra Pak particle concentration or particle size is increased, as regularly occurs in composite materials. Nevertheless, improvements of $14 \%$ on both compressive strength and flexural strength as well as $5 \%$ for modulus of elasticity were obtained when polymer concrete is irradiated.

\section{Introduction}

Cement concrete is the most widely used structural material in the world, due to its easy preparation and low cost. Some disadvantages of cement concrete are (a) pores, which can become entrance points for water, gases, water vapor, and chemical substances that might damage concrete; (b) the roughness of concrete surface that deteriorates rapidly because of its high abrasion; (c) poor resistance to aggressive substances and salty water; (d) low resistance to heat. One alternative for such problems is the incorporation of natural or synthetic polymeric materials into concrete, which have good binding with mineral aggregates of concrete.

Such kinds of materials promote the development of polymer-based materials with improved physicochemical properties. In fact, composite materials include a matrix (continuous phase) and reinforcement (discrete phase). The material chosen as the matrix generally is less strong and rigid than the reinforcing material. In general, the reinforcement is used to increase the mechanical strength and rigidity; some reinforcements are also used to improve high temperature performance and abrasion resistance. Moreover, with synthetic polymers it is possible to produce more flexible and cheaper materials [1-4].

Among the composite materials for civil engineering applications, polymer concrete has a preferential place. This is a composite material produced from inorganic aggregates (such as sand, gravel, or fly ash) bonded together by a polymeric binder (or plastic glue), instead of water and cement binder typically used in cement concrete. Polymeric 
binder can be thermoplastic or more frequently a thermosetting material. Currently polymer concrete is used for the production of industrial flooring, countertops for bathrooms and kitchens, saunas, water storage tanks, and prefabricated structures used in the field of construction. It is also used in electrical applications such as insulators for high voltage transmission, support for isolation bushings, and solid-core insulation [5-8].

Nowadays, because of the more stringent legislation regarding the environment and the market demand for environmentally-friendly products, manufacturers are concerned with developing studies aimed at reducing the environmental impact, through lowering the amount of produced residues or by treating those that are inevitably generated during production processes. High costs associated with raw material extraction, as well as the damage that extraction causes to environment, are also important reasons to motivate the use of domestic and industrial residues. Depletion of reliable, trustable raw material reserves and conservation of nonrenewable sources also contribute to reusing waste materials.

Recycling of engineering materials will contribute to the sustainability and development of industrial processes. Nowadays, metals, glass, thermal plastics, and many other engineering materials are recycled to a great extent. However, composite materials, as a special category of engineering materials, have not considerable progress in recycling, due to its heterogeneous composition [9].

In recent years, various tools and strategies have been proposed to meet environmental challenges in the building industry: (a) increasing the use of waste materials, especially those that are by-products of industrial processes; (b) using recycled materials instead of natural resources (this will make the industry more sustainable); and (c) improving durability, mechanical and other properties, by reducing the amount of materials required for replacement [10-16].

Extensive research and development activities in recycling composite materials have been conducted, and various technologies have been developed in three categories: (a) mechanical recycling, (b) thermal recycling, and (c) chemical recycling. Mechanical recycling involves shredding and grinding, followed by screening to separate the component fractions for reuse. Thermal processing uses high temperature to decompose the resin and separate the reinforcements $\left(300-1000^{\circ} \mathrm{C}\right)$. Moreover, secondary fuel or thermal energy is produced through pyrolysis, gasification, or combustion. Finally, chemical recycling allows depolymerization or removal of the matrix and liberation of the reinforcements for further recycling by using an organic or inorganic solvent. A cleaner process based on water technology has gained more attention in the research world and shown an interesting potential [9, 17-21].

A few investigations have been carried out on the use of recycled polymeric materials in concrete, covering different objectives as (a) recycled PET of bottles for producing very good quality polymer concrete with low cost for structural applications [22, 23]; (b) waste plastic aggregates for producing lightweight concrete with low thermal conductivity and reduced values of compressive and tensile strength when
TABLE 1: Polymer concrete components.

\begin{tabular}{lccc}
\hline $\begin{array}{l}\text { Lot } \\
\text { (code })\end{array}$ & $\begin{array}{c}\text { Resin } \\
(\%)\end{array}$ & $\begin{array}{c}\text { Sand } \\
(\%)\end{array}$ & $\begin{array}{c}\text { Waste Tetra Pak particles } \\
(\%)\end{array}$ \\
\hline PC & 20 & 80 & 0 \\
PC-1 & 20 & 79 & 1 \\
PC-2 & 20 & 78 & 2 \\
PC-4 & 20 & 76 & 4 \\
PC-6 & 20 & 74 & 6 \\
\hline
\end{tabular}

the waste plastic concentration is increased [24]; (c) HDPE waste from trash bags as a potential replacement for coarse aggregate in concrete [25]; (d) ground plastic materials as substitute of fine aggregates (up to 20\%) in concrete [1]. Such recycling not only helps conserve natural resources, but also helps to solve a growing waste disposal crisis [26].

A lack of information is available regarding recycling of Tetra Pak constituent materials (polyethylene, cellulose, and aluminum) and their use as replacement of aggregates in polymer concrete. Containers such as Tetra Pak packaging have short useful life, becoming a trash and a serious problem for environment. Recycling of such packaging is low, compared with its high production of 26.4 billion packages in 2012, which were produced in 36 countries.

The Tetra Pak beverage containers are made from cellulose (75\%), low density polyethylene (20\%), and aluminum $(5 \%)$. Once the container is discarded, it can be recycled in three ways: (a) being incinerated to produce electricity, (b) being recycled for paper making, and (c) being used for production of sheets and chipboard products. Tetra Pak recycling process has many stages; first the containers are washed to remove traces of originally contained products and after the mechanical grinding process is effected. It is important to mention that cellulose located at inner layers of the container makes it difficult to remove the water absorbed during the washing process; moreover, high content of hydroxyl groups of cellulose fibers makes them susceptible to water absorption.

However, an optional recycling way for Tetra Pak packaging is its use as substitute of mineral aggregates in the elaboration of polymer concrete, improving its properties, including lower weight and density, higher mechanical strength, and toughness.

In this work the effect of waste Tetra Pak particles (from beverage packaging) on the mechanical properties of polymer concrete was studied. Such particles replaced partially siliceous sand in the polymer concrete, elaborated with polyester resin and siliceous sand. In addition, the effect of gamma radiation on the compressive and flexural strength was evaluated.

\section{Experimental}

2.1. Specimen Elaboration. Five different polymer concrete lots identified by different codes were prepared as seen in Table 1. For each lot six specimens were prepared. Standard prismatic molds $(40 \times 40 \times 160 \mathrm{~mm})$ were used to formulate 
polymer concrete specimens according to CPT PC-2 recommendation.

In the first stage, one lot of polymer concrete specimen (control concrete) was elaborated with a commercial unsaturated preaccelerated polyester resin (orthophthalic): a viscous liquid resin with a styrene monomer concentration of 30\% (Polylite 32493- 00, Reichhold, Atlacomulco, Mexico) and siliceous sand of a local company (GOSA, Tlalnepantla, Mexico). The polymer concrete specimens had a composition of $20 \%$ by mass of polyester resin and $80 \%$ by mass of siliceous sand. The sand had uniform granulometry with an average diameter of $0.25 \mathrm{~mm}$ (mesh 60).

The proportion of the initiator methyl ethyl ketone peroxide (MEKP) added to the polymer resin for initiating the free-radical polymerization process was $1 \mathrm{~mL} / 100 \mathrm{~g}$ of the resin weight. After mixing for 5 minutes, the polymer concrete specimens were placed in a controlled temperature room at $30.0 \pm 3.0^{\circ} \mathrm{C}$ up to 24 hours.

In the second stage, four lots of polymer concrete specimens were elaborated, but now siliceous sand was partially substituted by Tetra Pak particles (see Table 1), in different concentrations (1,2,4, and $6 \%$ by mass). The Tetra Pak particle sizes were bigger than those for siliceous sand, for covering a homogenous distribution of sizes: Tetra Pak particles: $0.85 \mathrm{~mm}, 1.40 \mathrm{~mm}$, and $2.36 \mathrm{~mm}$ (mesh 20, mesh 14, and mesh 8, resp.) and siliceous sand: $0.25 \mathrm{~mm}$ (mesh 60).

2.2. Mechanical Tests. The mechanical tests of polymer concrete specimens were carried out in a Controls Universal testing machine, with a load cell of 30 tons. The compressive testing is at a loading rate of $1.25 \mathrm{~mm} / \mathrm{min}$, holding the charge until reaching the maximum value to assure the reliability of the test; according to the UNE 83821:1992 standard test, it is important to mention that six specimens of each lot were elaborated for compressive testing.

The flexural testing at a loading rate of $1 \mathrm{~mm} / \mathrm{min}$ was according to CPTPCM-8 standard for three-point bending test. Load-displacement curves and the maximum load for the collapse bending were recorded. Each lot of the six elaborated specimens was submitted to flexural testing.

\subsection{Gamma Radiation. The polymer concretes specimens} were exposed to varying gamma radiation doses using ${ }^{60} \mathrm{Co}$ pencils of 5.2 years of life on average. The experiments were performed in air at room temperature; the dosages were 100 and $200 \mathrm{kGy}$ at the dose rate of $3.5 \mathrm{kGy} / \mathrm{h}$. The irradiation was provided by a Transelektro Irradiator LGI01 manufactured by IZOTOP Institute of Isotopes Co., Ltd. (Budapest, Hungary) and located at the National Institute of Nuclear Research (ININ, Mexico).

\section{Results and Discussion}

3.1. Compressive Strength. Figure 1 shows compressive strength of polymer concrete containing waste Tetra Pak particles. The compressive strength of concrete without particles (control concrete) is $90 \mathrm{MPa}$. The results were analyzed in terms of two parameters: concentration and size of the waste Tetra Pak particles. With respect to waste particle

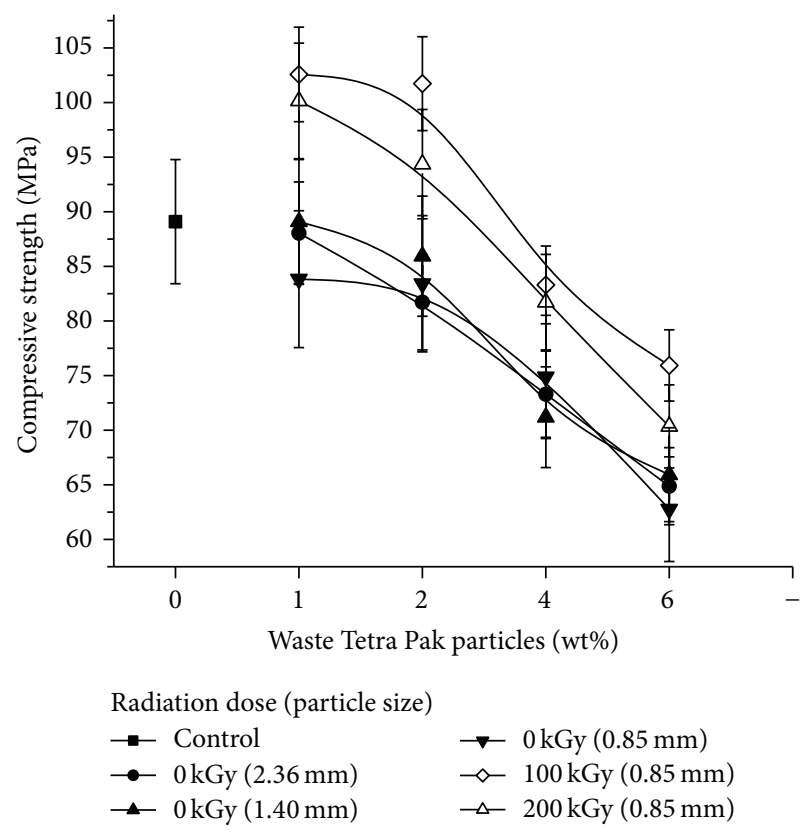

FIGURE 1: Compressive strength of polymer concrete in terms of waste particle size and irradiation dose.

concentration, increasing in the amount of added waste particles in the concrete specimens causes a gradual decrease in the compressive strength values. The lowest values were for concrete with $6 \%$ of waste particles, reducing in $28 \%$ compared with control concrete, namely, $65 \mathrm{MPa}$. Thus, waste particle concentration is a determining parameter for compressive strength of the polymer concrete. In terms of the particle size, for each particle concentration only small variations in the values were found. Thus, the particle size does not have major influence on the compressive strength.

Reduction in the compressive values can be attributed to the inefficient transfer of stresses between polymer concrete and Tetra Pak particles, which is consequence of (a) poor interaction between polymer concrete components (polyester resin and silica) and polyethylene layers of Tetra Pak containers and (b) poor adhesion between the two hydrophobic materials: polyester resin (matrix) and cellulose (from Tetra Pak containers). Despite the drying process of Tetra Pak particles prior to the preparation of concrete specimens, some moisture remained and acted as releasing agent on the waste particles-resin interface, consequently affecting the polymer concrete properties.

As was mentioned, reductions in the compressive values are attributed to the increment of particles concentration. It was corroborated with the surface morphology of the polymer concrete. Smooth and homogeneous surface on polymer concrete without Tetra Pak particles is appreciated in Figure 2(a); such surface is maintained and nonparticle agglomerations are observed when adding $2 \mathrm{wt} \%$ of Tetra Pak particles (Figure 2(b)). Nevertheless, for higher concentrations of particles, a rougher surface is appreciated (Figures $2(c)$ and 2(d)). Because there are no chemical interactions between polyester resin and waste particles, decreases of the 


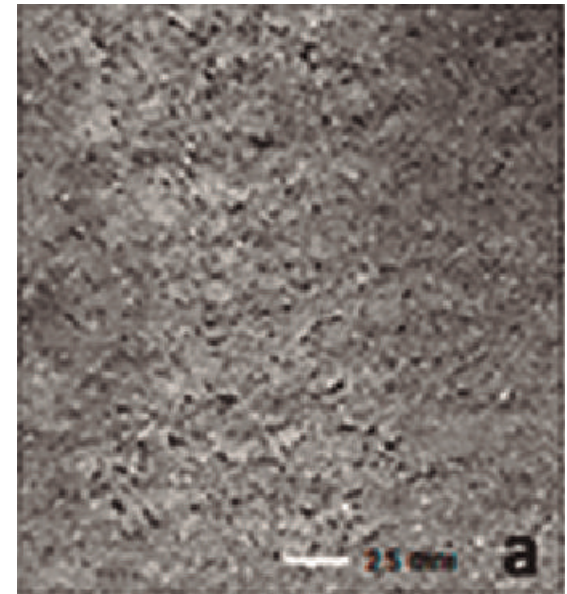

(a)

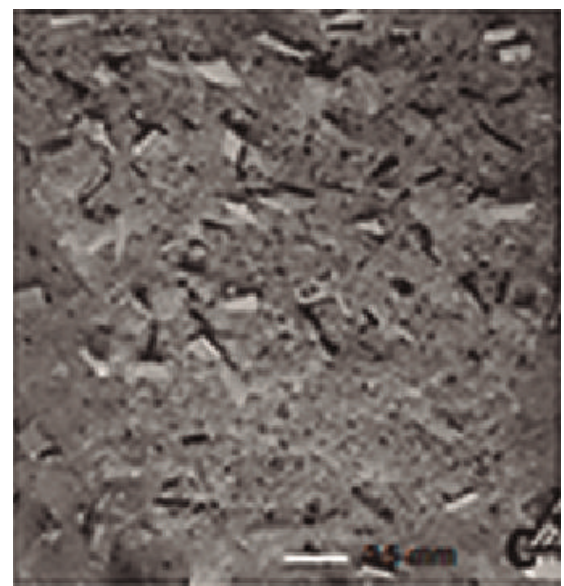

(c)

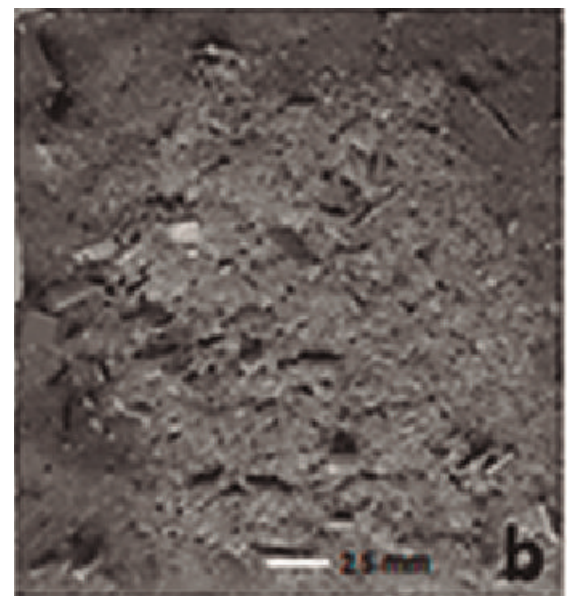

(b)

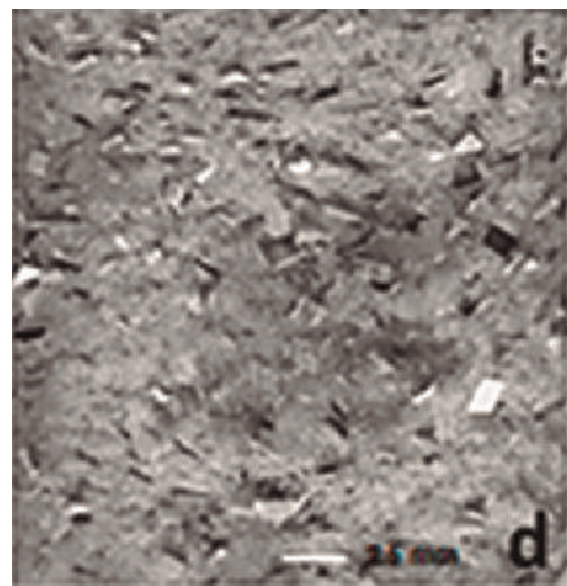

(d)

Figure 2: Polymer concrete (a) without Tetra Pak particles and with (b) $2 \mathrm{wt} \%$, (c) $4 \mathrm{wt} \%$, and (d) $6 \mathrm{wt} \%$.

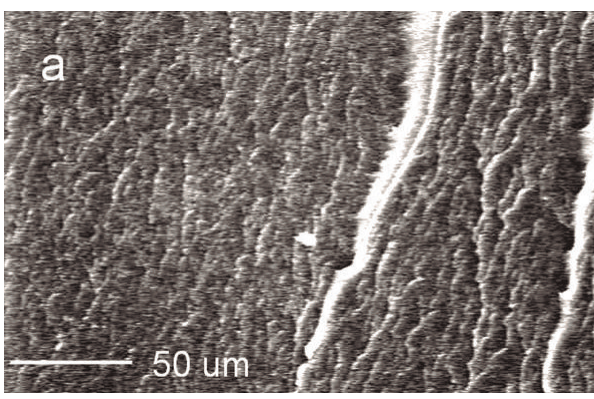

(a)

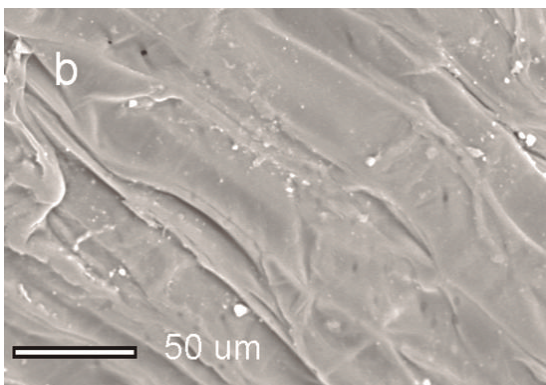

(b)

FIGURE 3: SEM images of irradiated (a) polyester resin matrix and (b) cellulose from Tetra Pak containers, at $200 \mathrm{kGy.}$

strength are consequence of the noninteractions between resin and Tetra Pak particles.

Because particle size does not have major influence on the compressive strength values, the polymer concrete with waste particle size of $0.85 \mathrm{~mm}$ was used to carry out the irradiation process.

In Figure 1, two different behaviors are appreciated for irradiated polymer concrete: (a) there is increment on the compressive strength for low concentrations of Tetra Pak particles ( 1 and $2 \mathrm{wt} \%$ ); such increments are 14\% higher than those for simple polymer concrete, which are attributed to the gamma irradiation effects caused in polyester resin as well as in polyethylene and cellulose of the Tetra Pak particles [27-29]; (b) for higher particle concentrations (4 and $6 \mathrm{wt} \%)$, more interactions between the resin matrix and Tetra Pak particles are present. Nevertheless, such particles are more crystalline and generate some pores in the polymer concrete; these pores act as flaws that do not allow an 

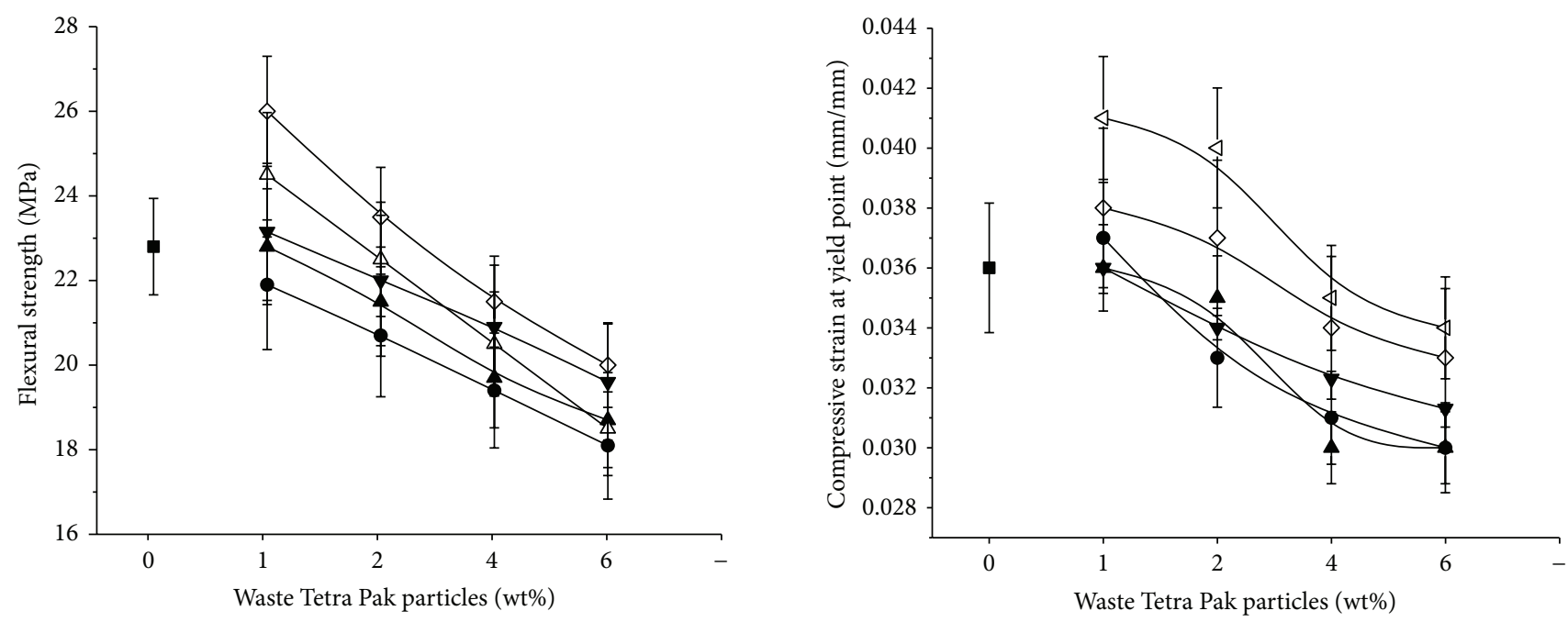

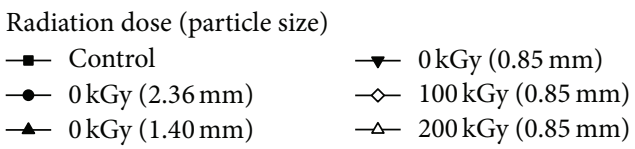

FIGURE 4: Flexural strength of polymer concrete containing waste Tetra Pak particles.

efficient transfer of charges, resulting in low compressive strength.

The increments in the compressive strength values are due to a better interfacial interaction between resin matrix and Tetra Pak particles, which happen at physical level and not through chemical bonding between them. Such assertion is based on the surface topology of the polyester resin and cellulose after irradiation. In the case of polyester resin, cross-linking of the polymeric chains produces increment on crystallinity and in consequence a rougher surface is observed (Figure 3(a)), while for cellulose of Tetra Pak more tendency toward scission of the polymer chains is detected, producing detachment of some particles (Figure 3(b)) [30].

3.2. Flexural Strength. The flexural strength values of concrete with waste Tetra Pak particles are shown in Figure 4. With respect to waste particles concentration, the flexural strength values decrease when increasing the particles concentration. The lowest value is for concrete with $6 \%$ of waste particles, which is $21 \%$ lower compared with control concrete. On the other hand, for each concentration the flexural strength values are lower when adding highest particle size, $2.36 \mathrm{~mm}$. In the case of flexural strength, a moderated effect was observed with the different sizes of waste particles in the polymer concrete, in the same way as compressive strength behavior.

Gamma irradiation applied to polymer concrete improves the flexural strength values, mainly for concrete with $1 \%$ and $2 \%$ of waste particles. Such improvement is $14 \%$ higher than control concrete. For higher particle concentrations, the values decrease progressively to $12 \%$ lower than the control concrete. The diminution in the flexural values is more

$$
\begin{array}{ll}
\text { Radiation dose (particle size) } & \\
\rightarrow-\text { Control } & \rightarrow 0 \mathrm{kGy}(0.85 \mathrm{~mm}) \\
\rightarrow-0 \mathrm{kGy}(2.36 \mathrm{~mm}) & \smile-100 \mathrm{kGy}(0.85 \mathrm{~mm}) \\
\neg 0 \mathrm{kGy}(1.40 \mathrm{~mm}) & -\smile 200 \mathrm{kGy}(0.85 \mathrm{~mm})
\end{array}
$$

FIGURE 5: Compressive strain at yield point of concrete containing waste Tetra Pak particles.

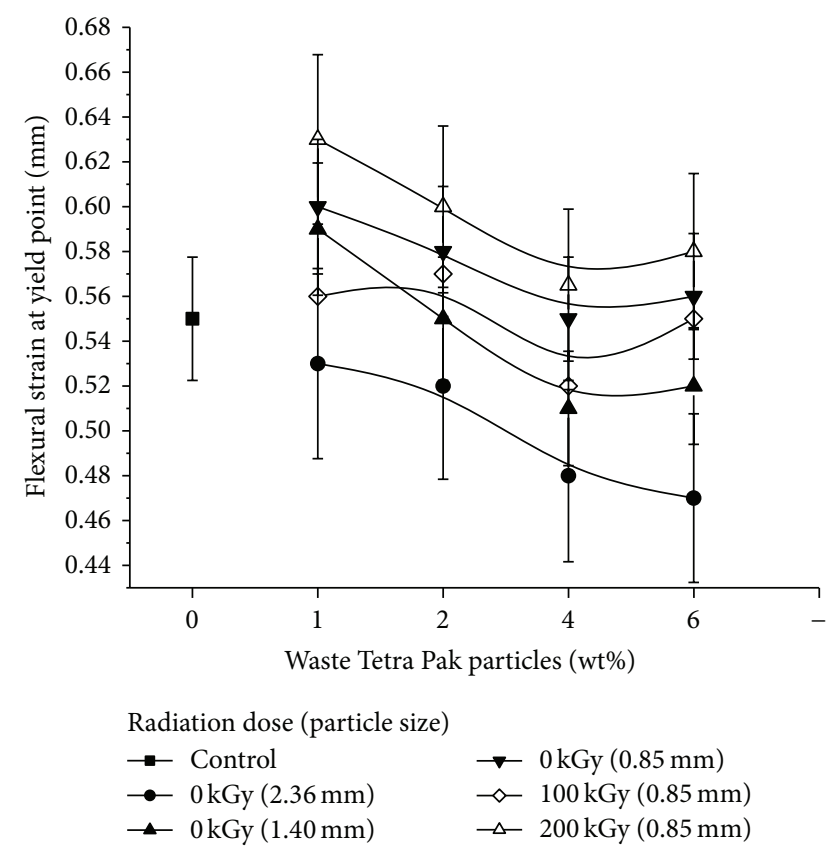

FIGURE 6: Flexural strain at yield point of concrete containing waste Tetra Pak particles.

notable when adding larger particle sizes that do not have uniform distribution in the polymer concrete, affecting the adherence with the polyester resin.

3.3. Compressive Strain at Yield Point. The compressive strains at yield point values are shown in Figure 5. In the case of control concrete, the value of $0.0036 \mathrm{~mm} / \mathrm{mm}$ is lower than the standard polymer concrete reported in the literature, 


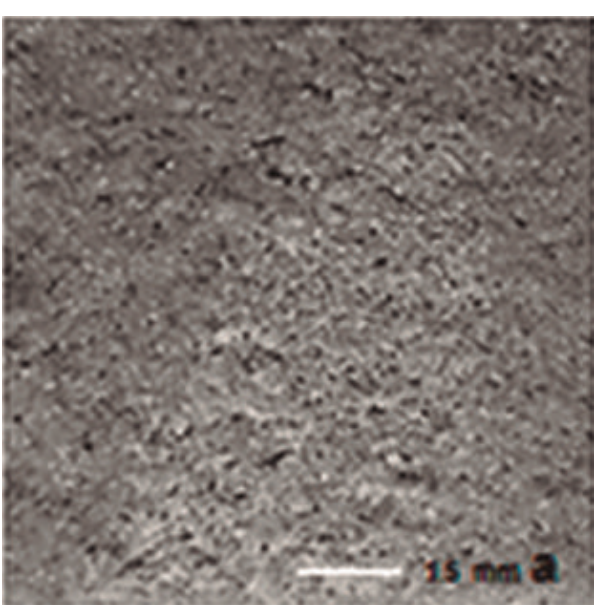

(a)

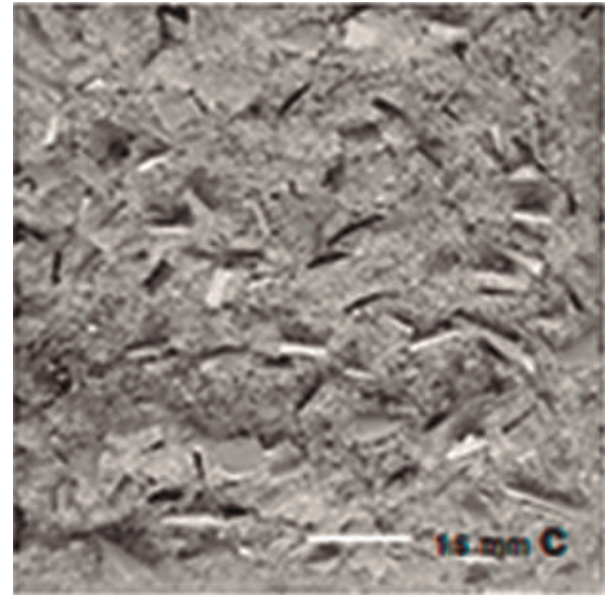

(c)

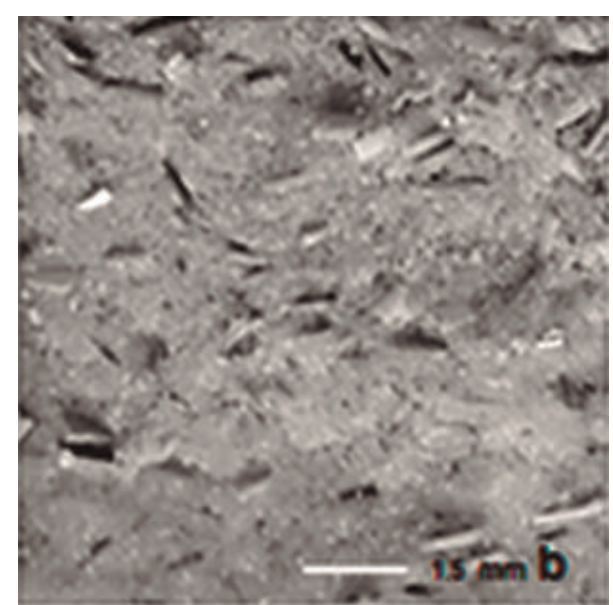

(b)

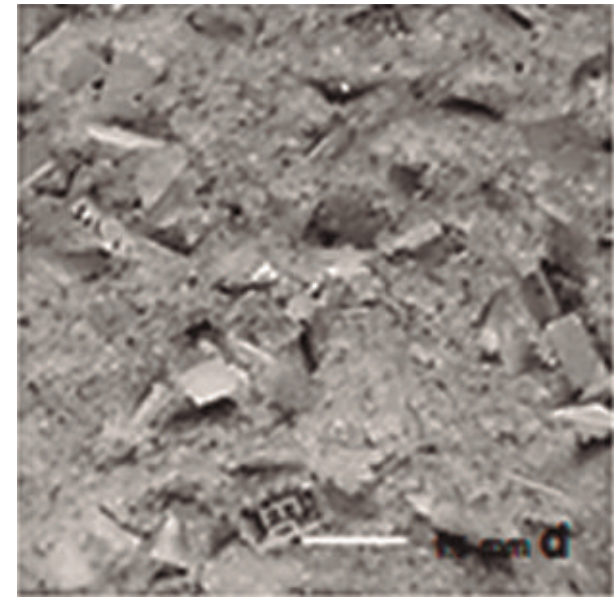

(d)

Figure 7: Polymer concrete without Tetra Pak particles (a) and with $1 \mathrm{wt} \%$ at different size; (b) $0.85 \mathrm{~mm}$, (c) $1.40 \mathrm{~mm}$, and (d) $2.36 \mathrm{~mm}$.

namely, $0.006 \mathrm{~mm} / \mathrm{mm}$. Compressive strain values decrease progressively when adding waste particles. The lowest values are obtained for concrete with $6 \%$ of particles, which are $16 \%$ lower than control concrete. Nevertheless, a slight increment is observed for concrete with $1 \%$ of waste particles. In general, no significant variations on the values with respect to particle size were observed; thus certain strain stability was obtained.

When concrete is irradiated, a maximum improvement of $6 \%$ is obtained for concrete with $1 \%$ or $2 \%$ of particle concentrations and irradiated at higher dose (200 kGy). For concrete with higher particle concentrations a detrimental behavior of flexural strength is observed with lower values. These changes are attributed to the ionizing energy, which produces concrete with higher ductility; that is, the deformation occurs in a sustainable way before reaching the breaking point.

3.4. Flexural Strain at Yield Point. In the case of flexural strain values, significant changes were observed, as follows: with respect to particle concentrations, flexural strain value decreases when adding waste Tetra Pak particles; the highest values were obtained for $1 \%$ or $2 \%$ of particle concentrations (Figure 6). With respect to particle sizes, (a) improvements up to $8 \%$ on the values were obtained when lowest size particles $(0.85 \mathrm{~mm})$ were added; thus a more ductile concrete is obtained; (b) by contrary, lowest values were obtained for concrete with large size particles $(2.36 \mathrm{~mm})$, being $12 \%$ lower than that for control concrete.

In the case of irradiated polymer concrete, by irradiating at $100 \mathrm{kGy}$, concrete deformation decreases up to $6 \%$, for concrete with $6 \mathrm{wt} \%$ of waste particles. Nevertheless, for a dose of $200 \mathrm{kGy}$, the strain property is improved by $14 \%$. Such improvement can be attributed to the stress transfer between polymer matrix and waste particles; it is effective for concrete with low concentrations (less than $4 \mathrm{wt} \%$ ) of waste particles of size of $0.85 \mathrm{~mm}$. As it is appreciated, a homogeneous surface for control concrete (without particles) is observed (Figure 7(a)) which presents changes when particles are added. Concrete with particles of $0.85 \mathrm{~mm}$ has the highest value of flexural strain values, which can be related to a greater contact area between the particles and the concrete matrix; thus the stress transfer is greater; moreover homogenous surface and good distribution of the particles are observed (Figure 7(b)), while for higher particle concentrations the values decrease and they are attributed to irregular distributions of particles (Figures $7(\mathrm{c})$ and $7(\mathrm{~d}))$. 


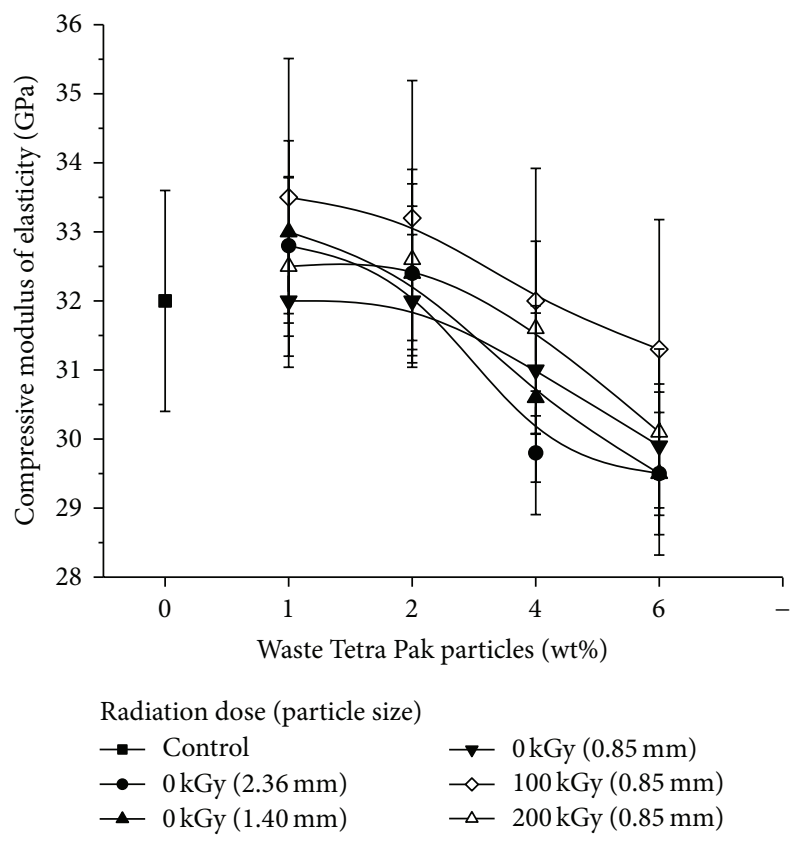

FIGURE 8: Compressive modulus of elasticity of polymer concrete at different particle concentrations.

3.5. Modulus of Elasticity. Figure 8 shows the modulus of elasticity for concrete containing waste particles. With respect to particle concentrations, a general behavior was observed: the values decrease gradually when increasing the addition of particles. Such diminution is consequence of the cellulose moisture. In fact, the water absorbed by the cellulose does not provide an efficient load transfer between polymer matrix and particles. It is important to mention that during polymer concrete elaboration temperatures over $130^{\circ} \mathrm{C}$ are reached by exothermic polymerization of resin; therefore the moisture in the cellulose can be evaporated and generate pores in polymeric matrix, which can modify mechanical properties of polymer concrete. The lowest value was obtained for concrete with $6 \%$ of waste particles, which means $10 \%$ lower than control concrete. With respect to particle size, slight variations in the values are observed.

Improvements of $5 \%$ are observed for irradiated concrete with $1 \%$ or $2 \%$ of waste particles; highest values were found with specimens irradiated at $100 \mathrm{kGy}$. The cross-linking effect caused by ionizing energy on the polymer matrix increases the resistance and thus Young's modulus increases [27].

\section{Conclusions}

In this work, the effects of the concentration and size of waste Tetra Pak particles (obtained from trash beverage bottles) on the compressive and flexural strength of polymer concrete were evaluated. The results show that the compressive and flexural strength and modulus of elasticity values decrease gradually when increasing the addition of waste particle concentration. A slight increment in the flexural strength values was observed for polymer concrete with smallest particle size. However, improvements of $14 \%$ were obtained for compressive and flexural strength when irradiating the concrete specimens at $100 \mathrm{kGy}$. Finally the modulus elasticity was improved by $5 \%$.

\section{Conflict of Interests}

The authors declare that none of them has a direct financial relationship with the commercial trademarks mentioned in this paper that might lead to a conflict of interests for any of the authors.

\section{Acknowledgments}

Financial support of the Autonomous University of the State of Mexico (UAEM), Toluca, by Grant UAEM 3886/2015FS is acknowledged. The authors thank National Council for Science and Technology of México (CONACYT) for the scholarship for one of the authors (Miguel Martínez-López) and Environmental Sciences Graduate Program of Universidad Autónoma del Estado de México (UAEM).

\section{References}

[1] M. Batayneh, I. Marie, and I. Asi, "Use of selected waste materials in concrete mixes," Waste Management, vol. 27, no. 12, pp. 1870-1876, 2007.

[2] M. Rahman, M. Islam, and M. Ahmed, "Recycling of waste polymeric materials as a partial replacement for aggregate in concrete," in Proceedings of the International Conference on Chemical, Environmental and Biological Sciences (ICCEBS '12), pp. 99-102, Penang, Malaysia, 2012.

[3] P. Soroushian, J. Plasencia, and S. Ravanbakhsh, "Assessment of reinforcing effects of recycled plastic and paper in concrete," ACI Materials Journal, vol. 100, no. 3, pp. 203-207, 2003.

[4] R. Siddique, J. Khatib, and I. Kaur, "Use of recycled plastic in concrete: a review," Waste Management, vol. 28, no. 10, pp. 18351852, 2008.

[5] M. C. S. Ribeiro, P. R. Nóvoa, A. J. M. Ferreira, and A. T. Marques, "Flexural performance of polyester and epoxy polymer mortars under severe thermal conditions," Cement \& Concrete Composites, vol. 26, no. 7, pp. 803-809, 2004.

[6] C. Vipulanandan and E. Paul, "Characterization of polyester polymer and polymer concrete," Journal of Materials in Civil Engineering, vol. 5, no. 1, pp. 62-82, 1993.

[7] G. Martínez-Barrera, C. Menchaca-Campos, and F. UreñaNuñez, "Gamma radiation as a novel technology for development of new generation concrete," in Gamma Radiation, F. Adrovic, Ed., pp. 91-114, InTech, Rijeka, Croatia, 2012.

[8] L. Czarnecki, "Polymer concretes," Cement, Wapno, Beton, no. 2, pp. 63-85, 2010.

[9] Y. Yang, R. Boom, B. Irion, D.-J. van Heerden, P. Kuiper, and H. de Wit, "Recycling of composite materials," Chemical Engineering and Processing: Process Intensification, vol. 51, pp. 53-68, 2012.

[10] K. S. Rebeiz, "Time-temperature properties of polymer concrete using recycled PET," Cement and Concrete Composites, vol. 17, no. 2, pp. 119-124, 1995.

[11] K.-S. Yeon, Y.-S. Choi, and S.-H. Hyun, "Properties of recycled polymer concrete using crushed polymer concrete as an aggregate," in Proceedings of the 2nd International Conference on 
Sustainable Construction Materials and Technologies, pp. 12991308, Ancona, Italy, June 2010.

[12] B.-W. Jo, S.-K. Park, and C.-H. Kim, "Mechanical properties of polyester polymer concrete using recycled polyethylene terephthalate," ACI Structural Journal, vol. 103, no. 2, pp. 219-225, 2006.

[13] J. M. L. Dos Reis and M. A. G. Jurumenh, "Experimental investigation on the effects of recycled aggregate on fracture behavior of polymer concrete," Materials Research, vol. 14, no. 3, pp. 326330, 2011.

[14] M. R. Ishak, Z. Leman, S. M. Sapuan, A. M. Edeerozey, and I. S. Othman, "Mechanical properties of kenaf bast and core fibre reinforced unsaturated polyester composites," IOP Conference Series: Materials Science and Engineering, vol. 11, Article ID 012006, 2010.

[15] M. E. Tawfik and S. B. Eskander, "Polymer concrete from marble wastes and recycled poly(ethylene terephthalate)," Journal of Elastomers and Plastics, vol. 38, no. 1, pp. 65-79, 2006.

[16] J. M. L. dos Reis, "Effect of textile waste on the mechanical properties of polymer concrete," Materials Research, vol. 12, no. 1, pp. 63-67, 2009.

[17] Y. Bai, Z. Wang, and L. Feng, "Chemical recycling of carbon fibers reinforced epoxy resin composites in oxygen in supercritical water," Materials and Design, vol. 31, no. 2, pp. 999-1002, 2010.

[18] J. M. Henshaw, "Recycling and disposal of polymer-matrix composites," in ASM Handbook, Volume 21: Composites, D. B. Miracle and S. L. Donaldson, Eds., pp. 1006-1012, ASM International, 2001.

[19] V. Goodship, Management, Recycling and Reuse of Waste Composites, WP, CRC Press, Cambridge, UK, 2010.

[20] S. Job, "Composite recycling-summary of recent research and development," Materials KTN Report, 2010.

[21] M. Blazsó, "Pyrolysis for recycling waste composites," in Management Recycling and Reuse of Waste Composites, V. Goodship, Ed., pp. 102-121, WP, CRC Press, Cambridge, UK, 2010.

[22] K. S. Rebeiz, S. P. Serhal, and D. W. Fowler, "Structural behavior of polymer concrete beams using recycled plastic," Journal of Materials in Civil Engineering, vol. 6, no. 1, pp. 150-165, 1994.

[23] G. Martínez-Barrera, C. Menchaca-Campos, C. E. BarreraDíaz, and L. I. Avila-Cordoba, "Recent developments in polymer recycling," in Gamma Rays: Technology, Applications and Health Implications, I. Bikit, Ed., pp. 237-256, Nova Science Publishers, Hauppauge, NY, USA, 2013.

[24] A. A. Al-Manaseer and T. R. Dalal, "Concrete containing plastic aggregates," Journal of Concrete International, vol. 19, no. 8, pp. 47-52, 1997.

[25] A. M. Mustafa, S. Mohammad, A. R. Rafiza, and Y. Zarina, "Investigation of HDPE plastic waste aggregate on the properties of concrete," Journal of Asian Scientific Research, vol. 1, pp. 340-345, 2011.

[26] G. Martínez-Barrera and O. Gencel, "Structural modification of waste materials and its use in building materials," in Photo Cured Materials, A. Tiwari and A. Polykarpov, Eds., pp. 347-359, Royal Society of Chemistry, Cambridge UK, 2015.

[27] W. E. Loos, "Effect of gamma radiation on the toughness of wood," Forest Products Journal, vol. 12, no. 5, pp. 261-264, 1992.

[28] Shuler CE, "Gamma irradiation effects on modulus of elasticity of engelman spruce," Forest Products Journal, vol. 21, no. 7, pp. 49-51, 1971.
[29] S. S. Cota, V. Vasconcelos, M. Senne Jr., L. L. Carvalho, D. B. Rezende, and R. F. Correa, "Changes in mechanical properties due to gamma irradiation of high-density polyethylene (HDPE)," Brazilian Journal of Chemical Engineering, vol. 24, no. 2, pp. 259-265, 2007.

[30] C. D. Nechifor, D. O. Dorohoi, and C. Ciobanu, "The influence of gamma radiations on physico-chemical properties of some polymer membranes," Condensed Matter, vol. 54, pp. 349-359, 2009. 

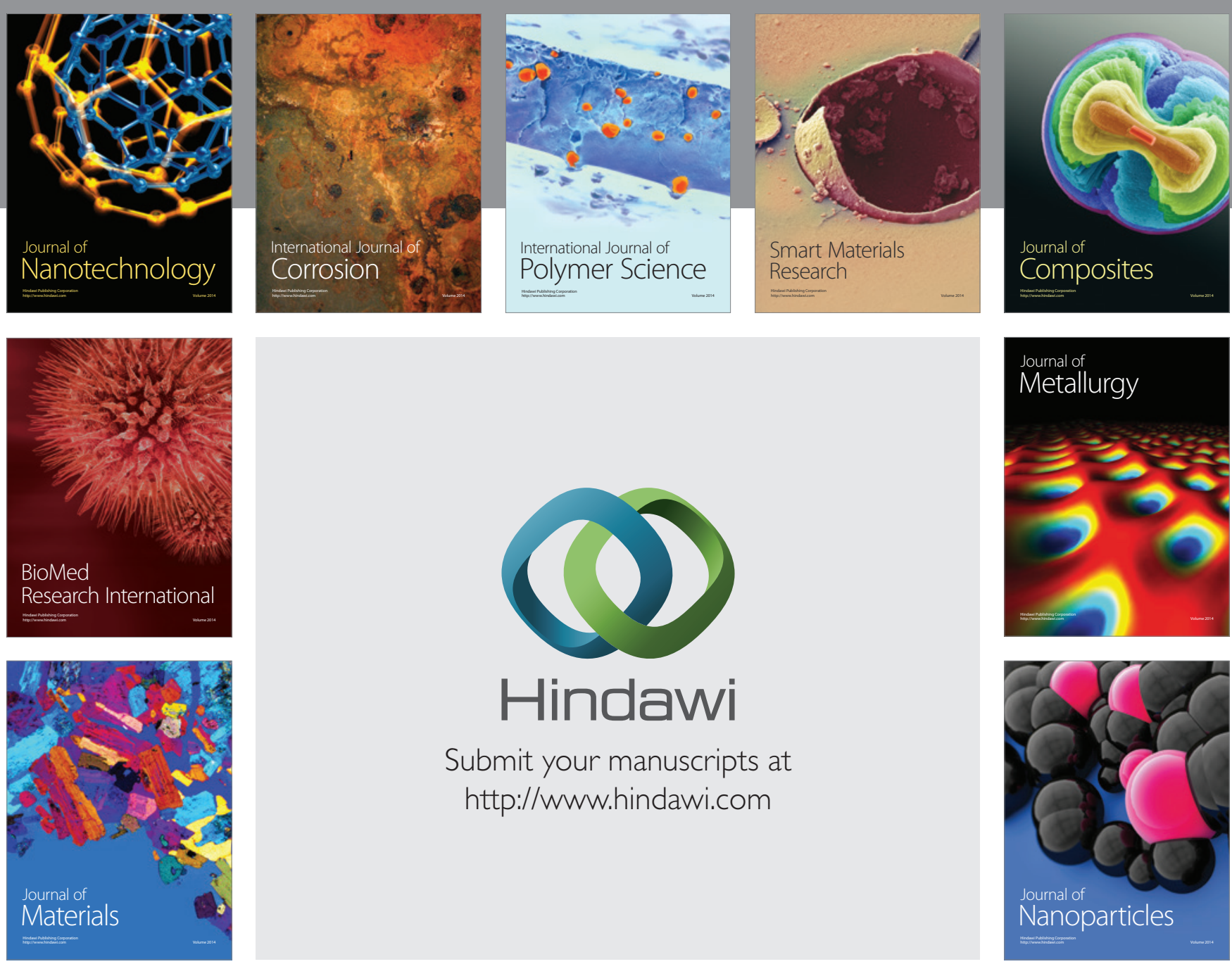

Submit your manuscripts at http://www.hindawi.com
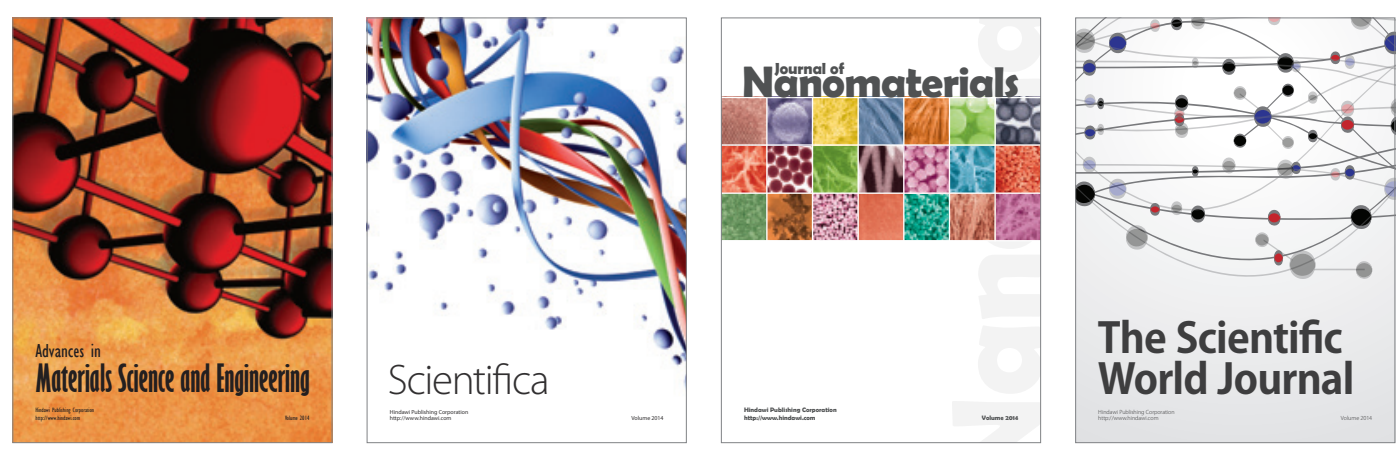

\section{The Scientific World Journal}
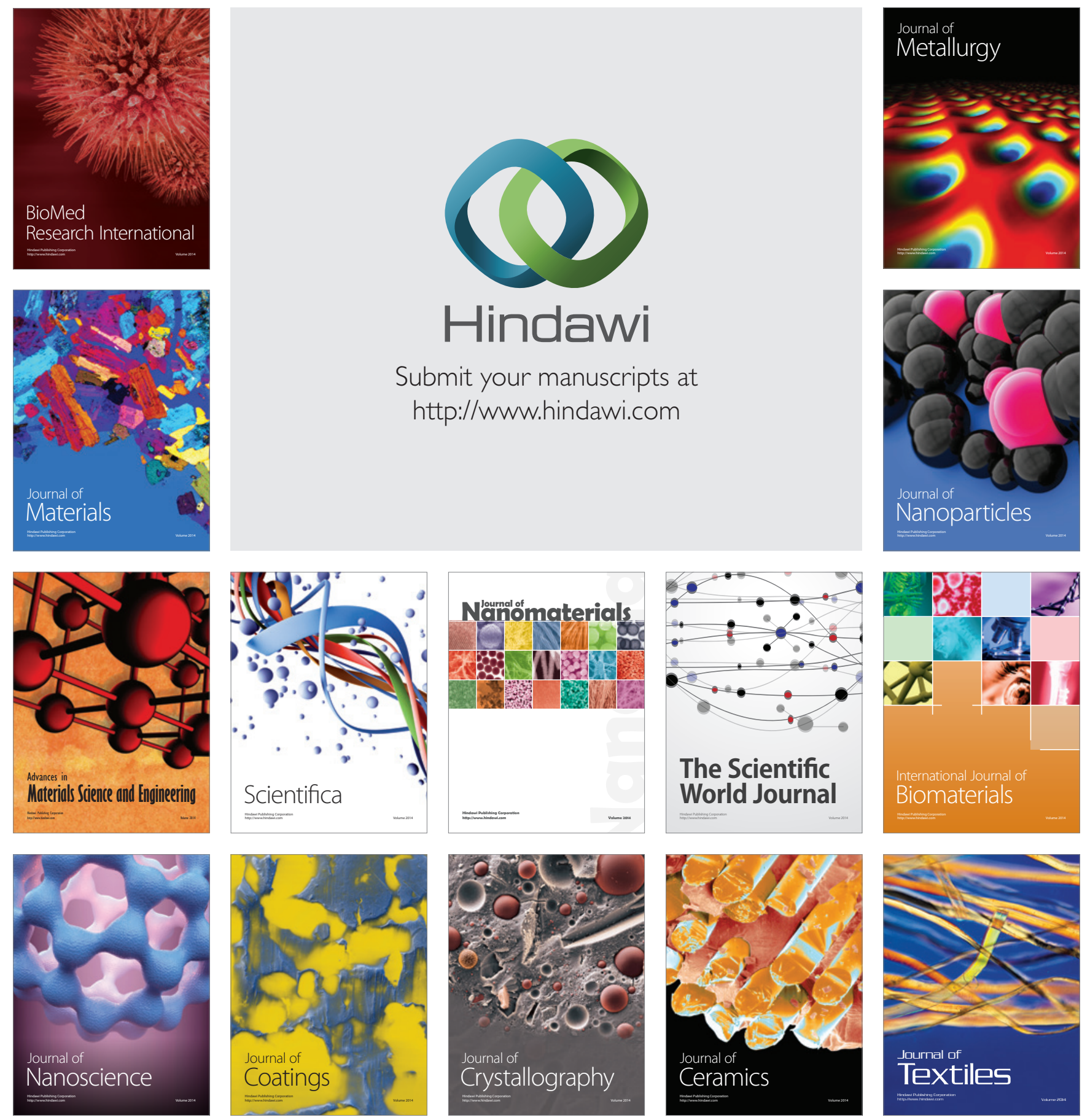